\title{
Verification of Vessel Fluence and Excore Modeling with VERA
}

Tara Pandya, ORNL Eva Davidson, ORNL Andrew Godfrey, ORNL Ben Collins, ORNL Shane Stimpson, ORNL

April 30, 2018
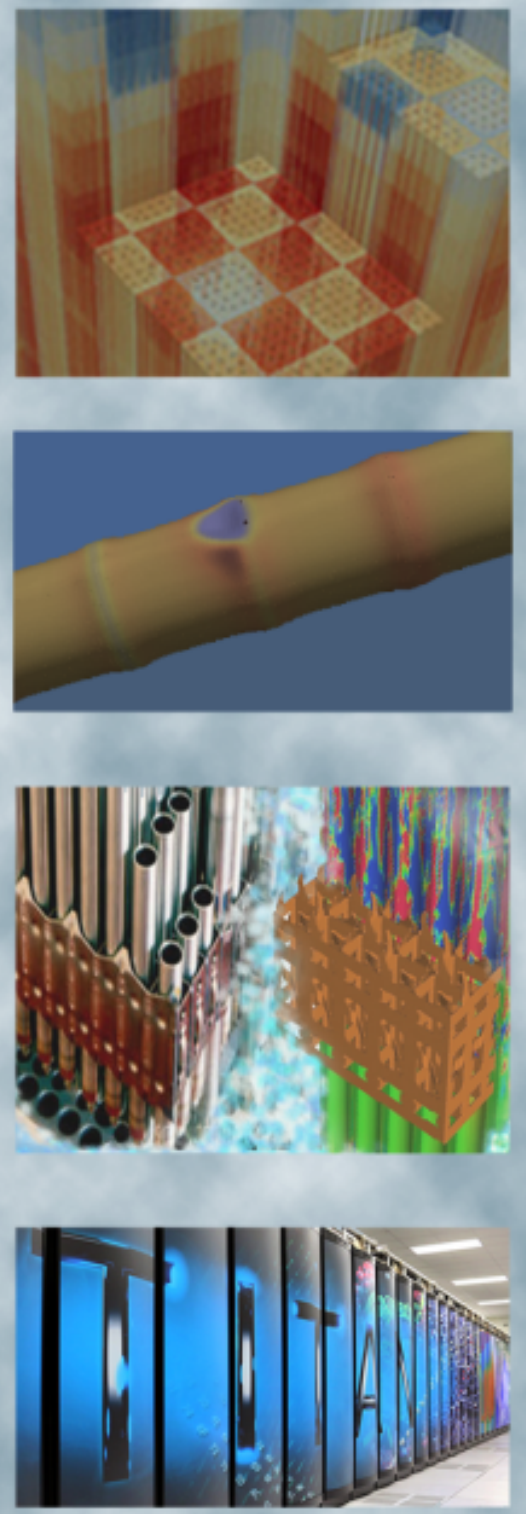

Approved for Public Release

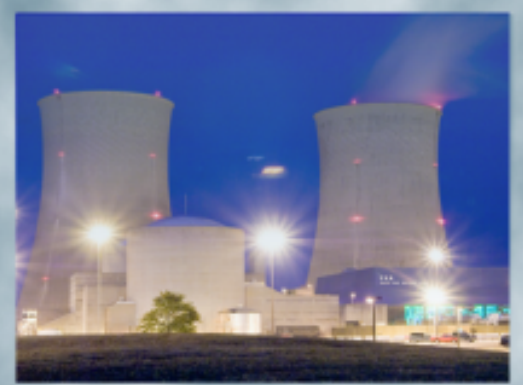




\section{DOCUMENT AVAILABILITY}

Reports produced after January 1, 1996, are generally available free via US Department of Energy (DOE) SciTech Connect.

Website http://www.osti.gov/scitech/

Reports produced before January 1, 1996, may be purchased by members of the public from the following source:

National Technical Information Service

5285 Port Royal Road

Springfield, VA 22161

Telephone 703-605-6000 (1-800-553-6847)

TDD 703-487-4639

Fax 703-605-6900

E-mail info@ntis.gov

Website http://www.ntis.gov/help/ordermethods.aspx

Reports are available to DOE employees, DOE contractors, Energy Technology Data Exchange representatives, and International Nuclear Information System representatives from the following source:

Office of Scientific and Technical Information

PO Box 62

Oak Ridge, TN 37831

Telephone 865-576-8401

Fax 865-576-5728

E-mail reports@osti.gov

Website http://www.osti.gov/contact.html

This report was prepared as an account of work sponsored by an
agency of the United States Government. Neither the United States
Government nor any agency thereof, nor any of their employees,
makes any warranty, express or implied, or assumes any legal liability
or responsibility for the accuracy, completeness, or usefulness of any
information, apparatus, product, or process disclosed, or represents
that its use would not infringe privately owned rights. Reference herein
to any specific commercial product, process, or service by trade name,
trademark, manufacturer, or otherwise, does not necessarily constitute
or imply its endorsement, recommendation, or favoring by the United
States Government or any agency thereof. The views and opinions of
authors expressed herein do not necessarily state or reflect those of
the United States Government or any agency thereof.


REVISION LOG

\begin{tabular}{|c|c|c|l|}
\hline Revision & Date & Affected Pages & \multicolumn{1}{c|}{ Revision Description } \\
\hline 0 & $08 / 06 / 2018$ & All & Initial Public Release - Unlimited \\
\hline & & & \\
\hline & & & \\
\hline & & & \\
\hline
\end{tabular}

\section{Document pages that are:}

Export Controlled None

IP/Proprietary/NDA Controlled None

Sensitive Controlled None

\section{Requested Distribution:}

To:

Bill Martin

Copy:

Thomas Evans

Kevin Clarno

Jeff Banta 


\section{EXECUTIVE SUMMARY}

This document outlines the completion of the L2:RTM.P17.01 milestone to deliver and report verification of vessel fluence and excore modeling capabilities in VERA to Advanced Modeling Applications (AMA). It gives details on the unit testing and initial verification of vessel fluence and excore detector calculations performed with VERA, as well as the plotting capabilities in VERAView. This capability is now ready for further testing and verification and validation by AMA. 


\section{CONTENTS}

EXECUTIVE SUMMARY $\ldots \ldots \ldots \ldots \ldots \ldots \ldots \ldots$ iv

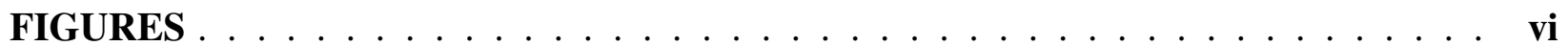

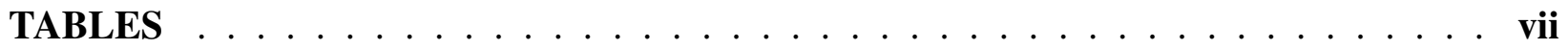

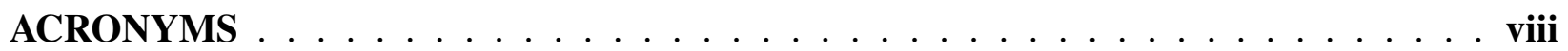

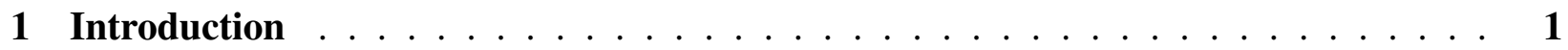

2 Task 1: Development and Integration $\ldots \ldots \ldots \ldots \ldots \ldots$

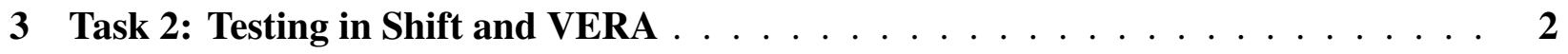

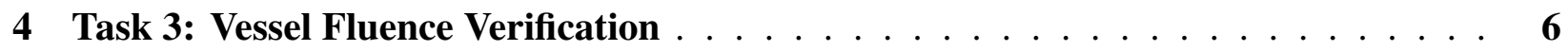

5 Task 4: Plotting in VERAView . . . . . . . . . . . . . . . . . . . . . . . 11

6 Task 5: Excore Detector Verification . . . . . . . . . . . . . . . . . . . . . . . . . . 14

7 Task 6: Documentation . . . . . . . . . . . . . . . . . . . . . . . . . 14

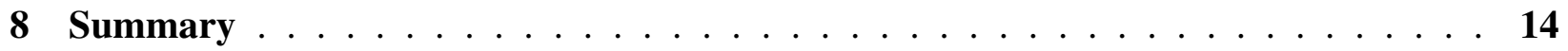

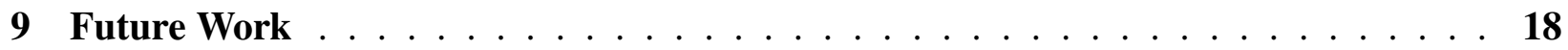




\section{FIGURES}

1 Fission source from MPACT for Progression Problem 9 statepoint 2 at the specified axial location in units of neutrons $/ \mathrm{cm}^{3}-\mathrm{s} . \ldots \ldots \ldots . \ldots 7$

2 Source region importance for Progression Problem 9 over all axial locations. . . . . 8

3 Maximum calculated fluence versus EFPY for Watts Bar Unit 1. . . . . . . . . . 10

4 Average calculated fluence rate per cycle for Watts Bar Unit 1. . . . . . . . . . . 11

5 Calculated vessel fluence for Watts Bar Unit 1 at EOC 15 plotted in VERAView. . . 13

6 Axial vessel fluence and pin power for Watts Bar Unit 1 at EOC 15 plotted in

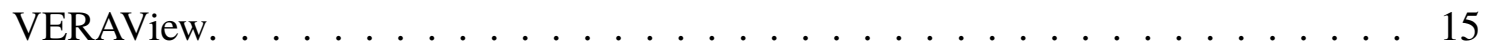

7 Axial slice of Harris PWR VERA model with excore detector (based on MCNP model provided by Duke Energy). . . . . . . . . . . . . . . . . 16

8 Calculated Harris PWR excore detector response change with moderator density. . 17 


\section{TABLES}

1 Relevant excore modeling unit/regression tests in VeraShift. . . . . . . . . . . . . 3

2 Relevant excore modeling unit/regression tests in VeraShift (continued). . . . . . . 4

3 Relevant excore modeling unit/regression tests in Exnihilo. . . . . . . . . . . . 5 


\section{ACRONYMS}

$\begin{array}{ll}\text { AMA } & \text { Advanced Modeling Applications } \\ \text { BOC } & \text { beginning-of-cycle } \\ \text { CADIS } & \text { Consistent Adjoint Driven Importance Sampling } \\ \text { CASL } & \text { Consortium for Advanced Simulation of Light Water Reactors } \\ \text { CTF } & \text { Coolant-Boiling in Rod Arrays-Two Fluids (COBRA-TF) } \\ \text { DOE } & \text { US Department of Energy } \\ \text { EFPD } & \text { effective full power days } \\ \text { EFPY } & \text { effective full power years } \\ \text { EOC } & \text { end-of-cycle } \\ \text { GG } & \text { Exnihilo general geometry } \\ \text { GIF } & \text { graphics interchange format } \\ \text { HFP } & \text { hot full power } \\ \text { MCNP } & \text { Monte Carlo N-Particle } \\ \text { PWR } & \text { pressurized water reactor } \\ \text { RTK } & \text { Reactor ToolKit }\end{array}$




\section{INTRODUCTION}

This report outlines the verification and completion of CASL L2:RTM.P17.01 milestone entitled Deliver Shift development and integration into VERA for excore detectors and vessel fluence to AMA. This milestone was established to provide working executables to AMA for testing and analysis of excore problems. The tasks laid out in the execution plan were:

1. Finish integration and development of CADIS calculations using Shift through VERA for vessel fluence and excore detector calculations.

2. Add tests in Exnihilo and VERA.

3. Run AMA-p7, AMA-p9, and multicycle Watts Bar models, and calculate vessel fluence to show that implementation is complete.

4. Plot vessel fluence in VERAView.

5. Run modified Watts Bar model with excore detector for multiple cycles and tally flux and reaction rates. Plot these results using python to show that implementation is complete.

6. Document the input, usage, output, and verification results.

The remainder of this document presents the completion evidence or verification performed for each of the tasks above; each section corresponds to an individual task. 


\section{TASK 1: DEVELOPMENT AND INTEGRATION}

The integration of running CADIS through Shift in VERA was completed for vessel fluence and excore detector calculations. This capability uses a deterministic adjoint calculation to give higher importance to particles reaching the vessel or excore detector regions. This is currently accomplished by taking advantage of weight windows in the Monte Carlo part of the calculation. Source biasing is not currently used, therefore the Shift calculation is not quite a true CADIS calculation. Once the updated implementation of source biasing in Shift is complete, it will be integrated into VERA. As with the usual forward Shift calculation, the fission source is transferred from MPACT to serve as the source for the Monte Carlo calculation.

There is only one outstanding issue with CADIS for excore detector calculations that is currently being corrected. This issue involves not properly extending the mesh and mixing multigroup cross sections for the adjoint calculation in the excore regions. The multigroup cross sections and mesh only cover the core region for the adjoint calculation. This means that the source is not being optimized in the vessel, but rather, only to the outer region of the core. While this issue has little effect on typical vessel fluence calculations, it does affect excore detector response calculations with VERA. Also note that this issue does not affect the flux calculated by Shift; only the number of particle histories that are needed to achieve a given statistical accuracy. The following section presents the unit tests added for CADIS vessel fluence and excore calculations with VERA.

\section{TASK 2: TESTING IN SHIFT AND VERA}

The following tests are included in VERA to cover the verification of excore and vessel fluence calculations. Tables 1 and 2 provide the names and brief descriptions of these tests, categorized according to the package in which they exist in VERA. Table 3 shows the tests in Exnihilo related to excore and vessel fluence. The initial list of excore tests was published in a CASL technical report that was provided to DOE last year [1]. 
Table 1. Relevant excore modeling unit/regression tests in

VeraShift.

\begin{tabular}{|c|c|}
\hline Test & Description \\
\hline \multicolumn{2}{|r|}{ VeraShift } \\
\hline tstDTK_Adapter_Full_Core & test mapping and fission grid using mini full core \\
\hline tstDTK_Adapter_Nonunique & test mapping and fission source on assemblies and small core without unique pins \\
\hline tstDTK_Adapter_Unique & test mapping, fission source, temperatures, densities, and isotopics on small core with unique pins \\
\hline tstDTK_Adapter_Unique_Inserts & test mapping, fission source, with unique pins including inserts \\
\hline & runs AMA_2a through vera_to_shift in eigenvalue mode; checks VERA input and comps \\
\hline $2 a \_c a d i s$ & $\begin{array}{l}\text { runs AMA_2a through vera_to_shift in CADIS mode with a dummy vessel; checks VERA input and } \\
\text { comps }\end{array}$ \\
\hline 2a_cadis_nonunique & $\begin{array}{l}\text { runs AMA_2a through vera_to_shift in CADIS mode with a dummy vessel and without unique pins; } \\
\text { checks VERA input and comps }\end{array}$ \\
\hline 2a_isotopes & $\begin{array}{l}\text { runs AMA_2a through vera_to_shift } \text { with dummy stainless steel including special nuclides to check } \\
\text { MPACT to Shift mapping }\end{array}$ \\
\hline 2a_forward & runs AMA_2a through vera_to_shift; checks VERA input and comps \\
\hline 2a_forward_nonunique & runs AMA_2a through vera_to_shift without unique pins; checks VERA input and comps \\
\hline & runs AMA_2e through vera_to_shift in eigenvalue mode; checks VERA input and comps \\
\hline $2 e$ forward & runs AMA_2e through vera_to_shift; checks VERA input and comps \\
\hline $2 e \_$forward_nonunique & runs AMA_2e through vera_to_shift without unique pins; checks VERA input and comps \\
\hline & $\begin{array}{l}\text { runs AMA_2o through vera_to_shift in eigenvalue mode with full isotopic tracking and coupling; } \\
\text { checks VERA input and comps }\end{array}$ \\
\hline
\end{tabular}


Table 2. Relevant excore modeling unit/regression tests in

VeraShift (continued).

\begin{tabular}{|c|c|}
\hline Test & Description \\
\hline \multicolumn{2}{|r|}{ VeraShift } \\
\hline 3_mini & $\begin{array}{l}\text { runs mini version of AMA_3a (minicore3) through vera_to_shift in eigenvalue mode; checks VERA } \\
\text { input and comps }\end{array}$ \\
\hline 3_mini_forward & runs minicore3 through vera_to_shift; checks VERA input and comps \\
\hline 3_mini_forward_nonunique & runs minicore3 through vera_to_shift without unique pins ; checks VERA input and comps \\
\hline $3 a$ & runs AMA_3a through vera_to_shift in eigenvalue mode; checks VERA input \\
\hline 3a_forward & runs AMA_3a through vera_to_shift; checks VERA input \\
\hline 4_mini_forward & runs mini version of AMA_4 through vera_to_shift; checks VERA input \\
\hline 4_mini_forward_nonunique & runs mini version of AMA_4 through vera_to_shift without unique pins; checks VERA input \\
\hline 5_mini_forward & runs mini version of AMA_5 through vera_to_shift; checks VERA input \\
\hline 5_mini_forward_nonunique & runs mini version of AMA_5 through vera_to_shift without unique pins ; checks VERA input \\
\hline multistate_noTH & runs multistate pincell problem through vera_to_shift in eigenvalue mode; checks VERA input \\
\hline multistate_internalCTF & $\begin{array}{l}\text { runs coupled multistate pincell problem through vera_to_shift in eigenvalue mode; checks VERA } \\
\text { input }\end{array}$ \\
\hline multistate_ctf_fulliso & $\begin{array}{l}\text { runs coupled multistate pincell problem through vera_to_shift in eigenvalue mode with full isotopic } \\
\text { tracking; checks VERA input }\end{array}$ \\
\hline small_core_cadis & $\begin{array}{l}\text { runs dummy small core with baffle and vessel through vera_to_shift in CADIS mode; checks VERA } \\
\text { input and comps }\end{array}$ \\
\hline small_core_excore & $\begin{array}{l}\text { runs dummy small core with vessel defined in excore file through vera_to_shift in forward mode; } \\
\text { checks VERA input }\end{array}$ \\
\hline small_core_excore_cadis & $\begin{array}{l}\text { runs dummy small core with vessel defined in excore file through vera_to_shift in CADIS mode; } \\
\text { checks VERA input }\end{array}$ \\
\hline
\end{tabular}


Table 3. Relevant excore modeling unit/regression tests in

Exnihilo.

\begin{tabular}{|c|c|}
\hline Test & Description \\
\hline \multicolumn{2}{|c|}{ Insilico } \\
\hline $\begin{array}{l}\text { generators/geometry/test/tstAsbly_Array_GG_PWR } \\
\text { generators/geometry/test/tstGG_Reactor } \\
\text { generators/geometry/test/tstExcore_Builder } \\
\text { generators/geometry/test/tstModel_Builder_GG_PWR } \\
\text { generators/geometry/test/tstReflector_Builder_GG_PWR } \\
\text { neutronics/test/tstSequence_Cadis } \\
\text { neutronics/test/tstSequence_Shift } \\
\text { neutronics/managers/test/tstManager_MC_Eigenvalue } \\
\text { neutronics/managers/test/tstManager_MC_FixedSource } \\
\text { neutronics/managers/test/tstManager_MC_FixedSource_Excore } \\
\text { rtk_md/rtk_metadata/test/tstCore_Vessel } \\
\text { rtk_md/rtk_model/test/tstCore_Vessel_Model } \\
\text { rtk_md/rtk_model/test/tstPWR_Core_Model }\end{array}$ & $\begin{array}{l}\text { multiple tests of the ability to make the GG assembly array } \\
\text { multiple tests of GG constructs for reactor core elements } \\
\text { excore detector geometry setup using GG input file } \\
\text { test builds the GG model from the RTK model } \\
\text { test builds the reflector region of the excore GG model } \\
\text { tests CADIS sequence logistics, including multistate } \\
\text { tests Shift eigenvalue and forward sequence logistics, including } \\
\text { multistate } \\
\text { tests the Shift solution procedure in eigenvalue mode given VERA } \\
\text { input } \\
\text { tests the full Shift forward solution procedure given VERA input } \\
\text { tests the full Shift excore solution procedure given VERA input, } \\
\text { including external excore file } \\
\text { tests setup of core vessel metadata, including barrel, pads, and } \\
\text { vessel } \\
\text { tests setup of core vessel model, including barrel, pads, and vessel } \\
\text { tests setup of vessel model as part of full PWR core }\end{array}$ \\
\hline
\end{tabular}




\section{TASK 3: VESSEL FLUENCE VERIFICATION}

The first step in vessel fluence verification was performed by running CASL AMA Progression Problems 7, 9, and 10 [2] with a vessel flux tally for neutrons above $1 \mathrm{MeV}$ added to the SHIFT block of the inputs. These problems were successfully run through VERA with Shift using forward and CADIS modes. Besides ensuring that the vessel flux for each statepoint was a reasonable order of magnitude and shape with VERAView, the fission source and adjoint flux were also analyzed. The following plots were made using the python post-processing tools available in Shift. Note that these plots are showing a model of the southeast quadrant of the reactor that is mirrored to the northeast quadrant for plotting purposes.

Figure 1 shows an axial slice of the fission source passed to Shift from MPACT for the second statepoint of Progression Problem 9. This source has the expected shape and magnitude. Figure 2 shows the importance of each source region to the vessel flux for Progression Problem 9. This importance was produced by folding the adjoint flux from the CADIS calculation with the fission source from the first statepoint over all axial locations. The regions shown in yellow are twice as important as those shown in light blue; the importance of interior pins drops dramatically in orders of magnitude toward the center of the core. This trend concurs with past evidence that only the source from peripheral pins is important to vessel fluence.

In addition to these progression problems, Andrew Godfrey ran and analyzed 15 cycles of Watts Bar Unit 1 vessel fluence calculated by VERA to serve as verification of this capability. All of these cycles ran successfully using CADIS mode, and the results were presented at the CASL Industry Council Meeting in Asheville, NC, on April 10, 2018 [3]. Details on these calculations include the following:

- Ran quarter-symmetry model;

- Simulated 19.9 EFPY using 335 statepoints;

- Used approximately 900 cores for the coupled MPACT and CTF part of the calculation;

- Used 100 cores for the Shift part of the calculation;

- Projected cycle 15 out to the designed end of cycle (EOC) burnup;

- Performed a typical core follow calculation with VERA:

- beginning of cycle (BOC) fuel shuffle,

- hot full power (HFP) cycle depletion following power, inlet temperature, and rod movement changes,

- Coupled MPACT, CTF, and ORIGEN for core calculations,

- BISON fuel temperature tables,

- Resonance upscatter option in MPACT multigroup library.

- Tallied vessel flux in Shift for each cycle using the following parameters:

- 32 azimuthal segments, 


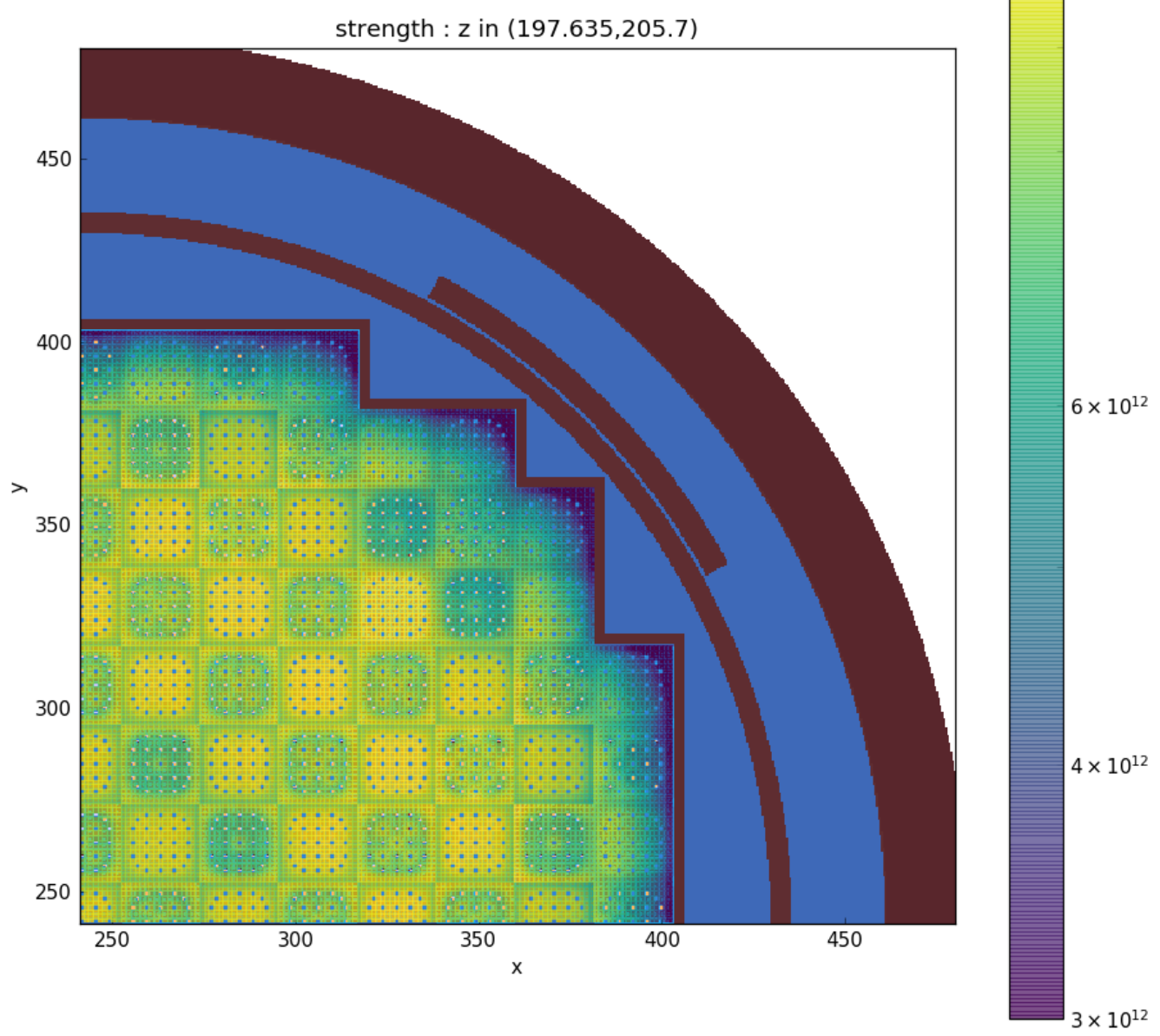

Figure 1. Fission source from MPACT for Progression Problem 9 statepoint 2 at the specified axial location in units of neutrons $/ \mathrm{cm}^{3}-\mathrm{s}$. 


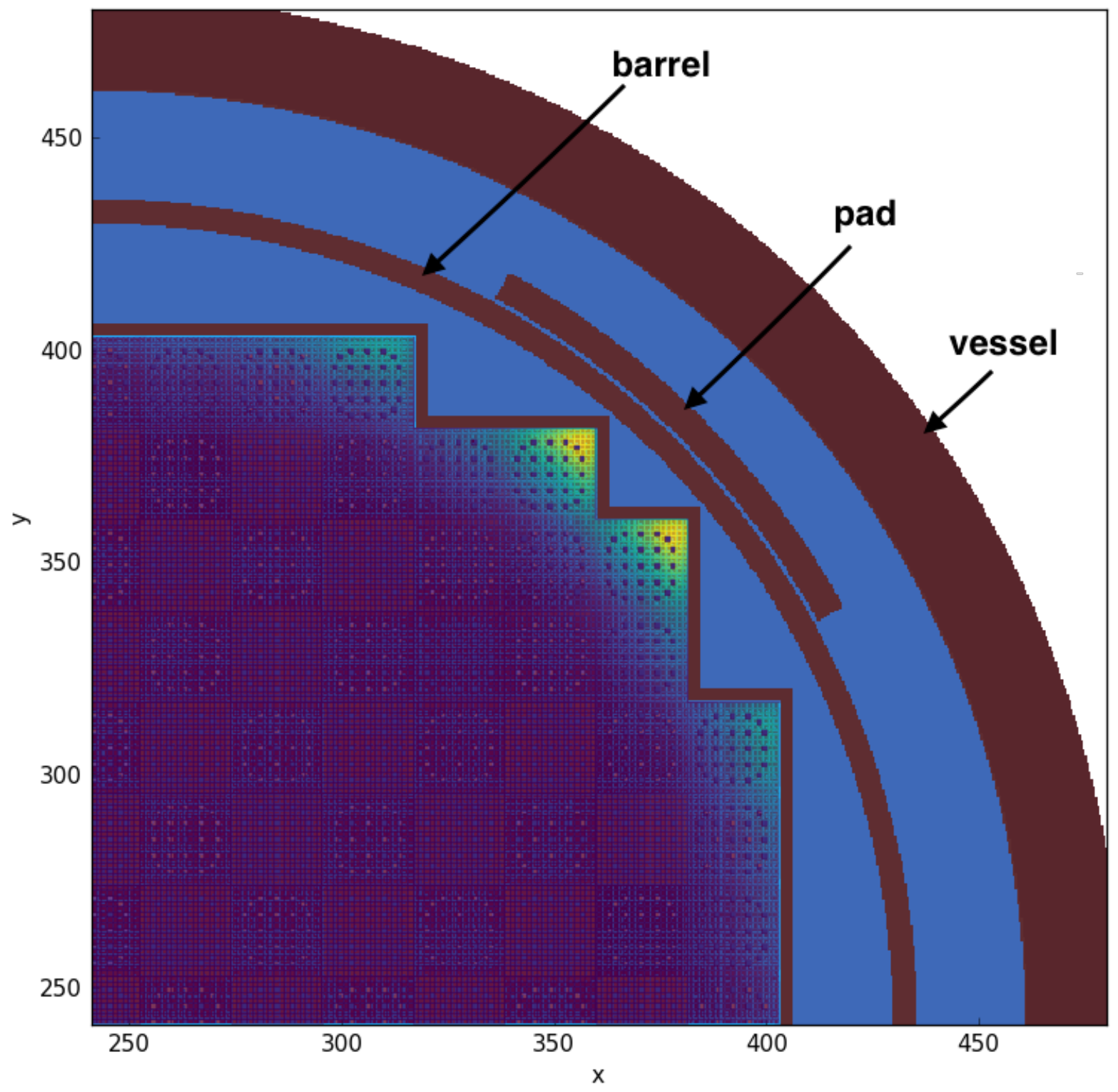

Figure 2. Source region importance for Progression Problem 9 over all axial locations (adjoint flux folded with the fission source for first depletion state). Magnitude is not shown here; change in color indicates stuff. 
- 11 radial rings,

- 49 uniform axial divisions from bottom grid plate to top grid plate,

- neutron flux over $1 \mathrm{MeV}$,

- $1 \times 10^{9}$ particle histories simulated for each Monte Carlo calculation.

Most of the results produced and presented at the Industry Council meeting were obtained using VERAView and are included in Section 5. As an initial verification, it was noted that the maximum vessel fluence for neutrons above $1 \mathrm{MeV}$ was found to be $\max =1.06 \times 10^{19}$ neutrons $/ \mathrm{cm}^{2}$. This value is comparable to a back-calculated max capsule fluence of $1.1 \times 10^{19}$ neutrons $/ \mathrm{cm}^{2}$ at 19.9 effective full power years (EFPY) (assuming a linear heating rate from $3.01 \times 10^{19}$ at 54 EFPY) taken from the Westinghouse analysis [4].

Figure 3 shows how the calculated maximum fluence rate changes versus EFPY. The power level of the reactor is also shown for reference. The main takeaway from this figure is that the change in fluence rate is not quite linear. There are times when higher and lower fluence rates deviate from linear heating. This trend is also seen in Fig. 4, which shows the average fluence rate per cycle. Ultimately, these preliminary verification results seem to show that VERA now has the ability to determine the effects of core design or operating regime changes on vessel fluence on a cycle-specific basis. 




Figure 3. Maximum calculated fluence versus EFPY for Watts

Bar Unit 1. The core power level is also shown for reference. Note that the maximum fluence rate is not quite linear over all 15 cycles. The statistical uncertainty associated with this calculated maximum fluence is not shown here but the departure from linear ranges from $-\mathbf{1 4 \%}$ to $+\mathbf{1 1 \%}$ over all cycles. 


\section{Average Fluence Rate By Cycle}

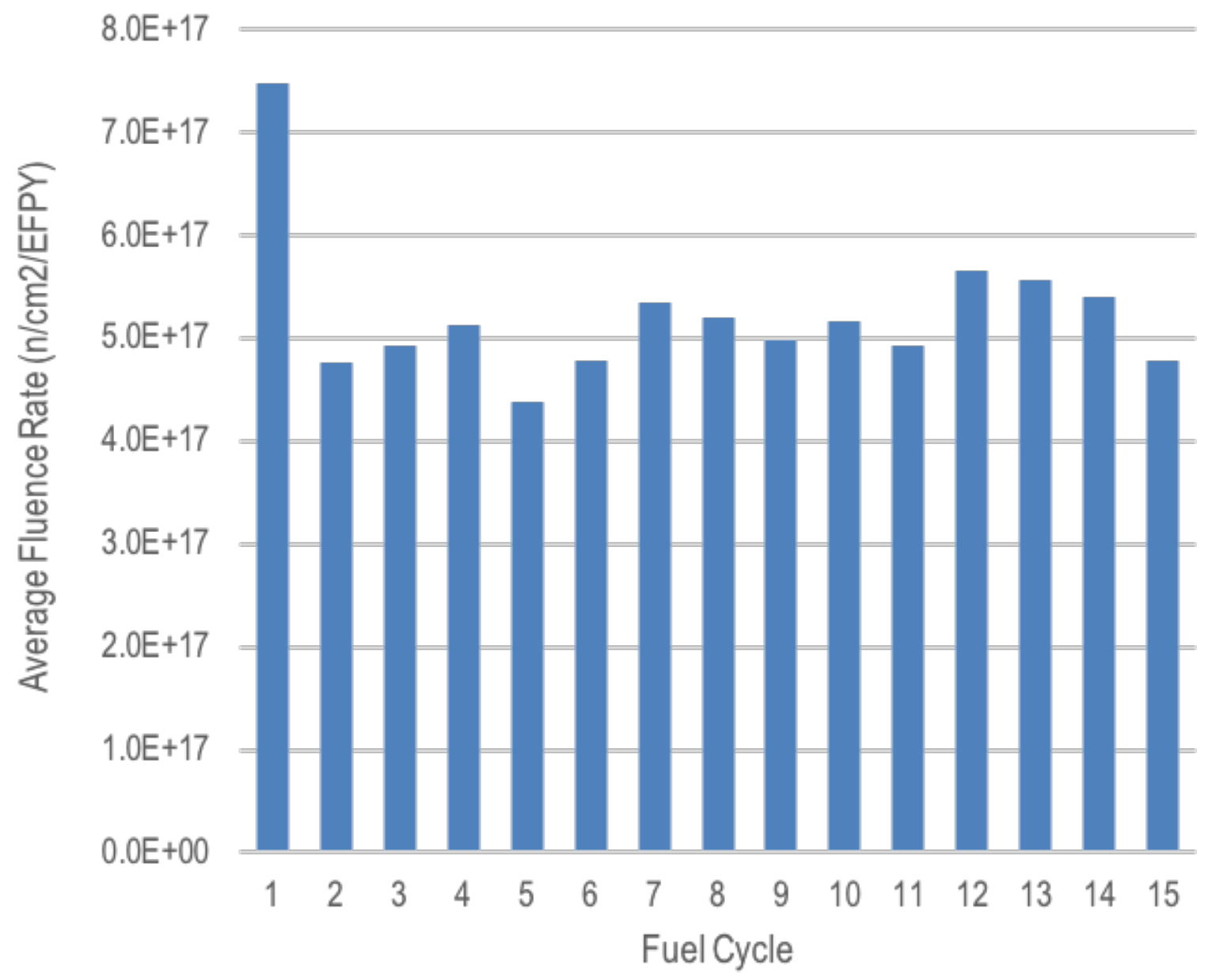

Figure 4. Average calculated fluence rate per cycle for Watts Bar Unit 1. Variations in cycle-to-cycle fluence rate can be seen.

\section{TASK 4: PLOTTING IN VERAVIEW}

As mentioned in the previous section, details of typical vessel fluence calculations can be plotted in VERAView. Currently, the vessel fluence is accumulated in VERAView. Fluence, $\phi(r, E)$, is defined as the time integration of the flux, $\phi(r, E, t)$, as given by

$$
\phi(r, E)=\int \phi(r, E, t) \mathrm{d} t .
$$

In practice, the fluence, $\phi_{M}^{g}(\boldsymbol{r})$, at a specific time step becomes

$$
\phi_{M}^{g}(\boldsymbol{r})=\sum_{m=0}^{M} \phi_{m}^{g}(\boldsymbol{r}) \Delta t_{m}
$$


where $M$ is the current time step and $g$ is the energy group. The flux, $\phi_{m}^{g}(\boldsymbol{r})$, in Eq. (2) comes from the energy-binned vessel tally for each state in the Shift HDF5 output file. The end time, $t_{m}$, in seconds for a given state is calculated using the effective full power days (EFPD) from the MPACT HDF5 output file using

$$
t_{m}=86400 \times \mathrm{EFPD}_{m} .
$$

Several animated graphical interchange formats (GIFs) were produced by Ron Lee showing the change in pin power and vessel fluence over all 15 cycles of Watts Bar Unit 1. These animated files can be provided upon request. Snapshots taken from these animated GIFs are shown below. Figure 5 shows the vessel fluence at the end of cycle 15 at the midplane of the reactor (an axial location of $\mathrm{z}=200.806 \mathrm{~cm}$ ) and at an angular direction of $\theta=43^{\circ}$. The linear heat rate in each pin is shown in the core, and the vessel fluence for neutrons above $1 \mathrm{MeV}$ is shown in the vessel. Note that the vessel fluence also has an associated relative error that is not shown here; this is calculated using the variance reported for the vessel flux in the Shift HDF5 output file. Vessel fluence relative error can also be plotted with VERAView; however, this feature is currently undergoing verification.

Figure 6 shows the corresponding axial vessel fluence at the inner vessel wall $(\mathrm{r}=219.7 \mathrm{~cm})$ and at an angular direction of $\theta=43^{\circ}$. The axial pin linear heat rate from the maximum pin location is also shown for reference. This figure shows the expected symmetry of the vessel fluence. 

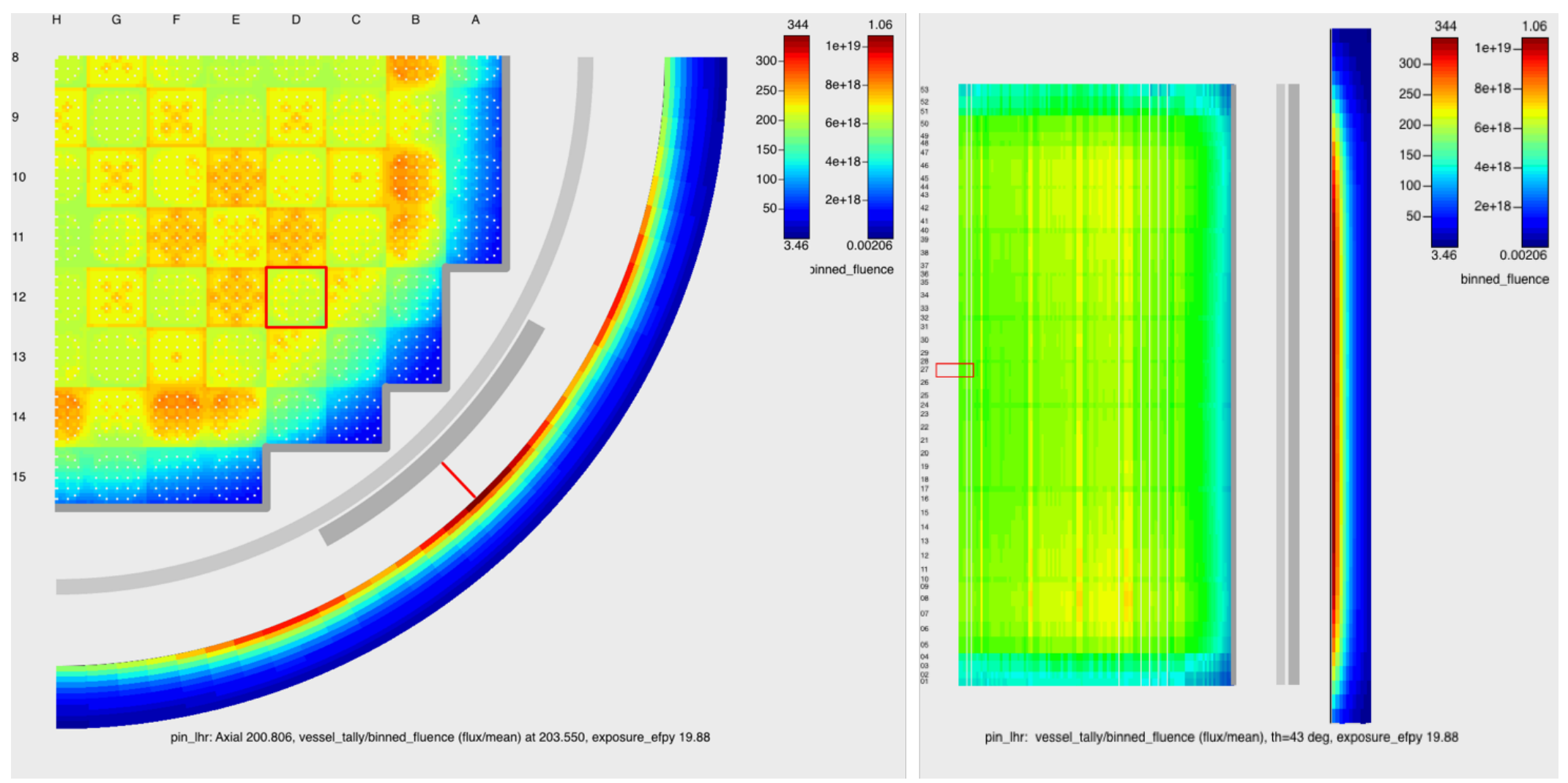

Figure 5. Calculated vessel fluence for Watts Bar Unit 1 at EOC 15 plotted in VERAView. 


\section{TASK 5: EXCORE DETECTOR VERIFICATION}

Eva Davidson performed the verification of the Watts Bar model with excore detectors added. The results of this verification are reported in the L3:AMA.RX.P16.05 milestone report entitled Testing of Omnibus General Geometry Models for Ex-Core Applications in VERA [5]. For this verification, a full core model of Watts Bar Unit 1 was developed with 4 power range detectors, 2 source range detectors, 2 dual surveillance capsules, and 2 single surveillance capsules. This report provides further details of this verification [5].

Beyond this application, verification and validation of this excore detector response capability was also presented at the CASL Industry Council Meeting in Asheville, NC, on April 10, 2018, by Eva Davidson [6]. The work presented was a collaboration with Herschel Smith at Duke Energy on modeling relative detector response of the Harris PWR.

A quarter-core model of the Harris PWR, including the excore detector, was developed for VERA by Eva Davidson and Andrew Godfrey (axial slice shown in Fig. 7). This model was run through VERA with varying moderator densities, and the detector response was calculated by Shift (item 1 below). To verify that the VERA calculation was correct, a total of four different calculations were compared.

1. VERA using Shift in forward mode,

2. Monte Carlo N-Particle (MCNP) eigenvalue calculation with particle splitting,

3. standalone Shift CADIS calculation using MCNP model for geometry and material specifications (run through the general Exnihilo frontend [7]),

4. standalone Shift eigenvalue calculation without particle splitting using MCNP model for geometry and material specifications (run through the general Exnihilo frontend).

Figure 8 shows the relative detector response versus moderator density for each of the simulations performed. The error bars shown are for one standard deviation. These results show excellent agreement in detector response between these four calculations.

\section{TASK 6: DOCUMENTATION}

Documentation of the input, usage, and output of excore calculations with VERA was delivered through two previous milestones. First, a manual entitled Excore Radiation Transport Modeling with VERA: Manual (CASL-U-2018-1556-000) was delivered in March 2018 under milestone L3:RTM.MCH.P16.02 [8]. It was released publicly in April 2018. Further documentation of the excore usage with VERA was delivered under milestone L3:AMA.RX.P16.05 with a report entitled Testing of Omnibus General Geometry Models for Ex-Core Applications in VERA (CASLU-2018-1561-000) [5]. This report and the AMA milestone serve as the evidence and completion of providing the preliminary verification results of excore modeling with VERA capability.

\section{SUMMARY}

The following tasks were completed as outlined in the execution plan of the L2:RTM.P17.01 milestone. 
Assy (D-12), exposure_efpy 19.88

vessel_tally/binned_fluence

Tally(flux/mean), $r=21 \overline{9} .7$, th $=43$

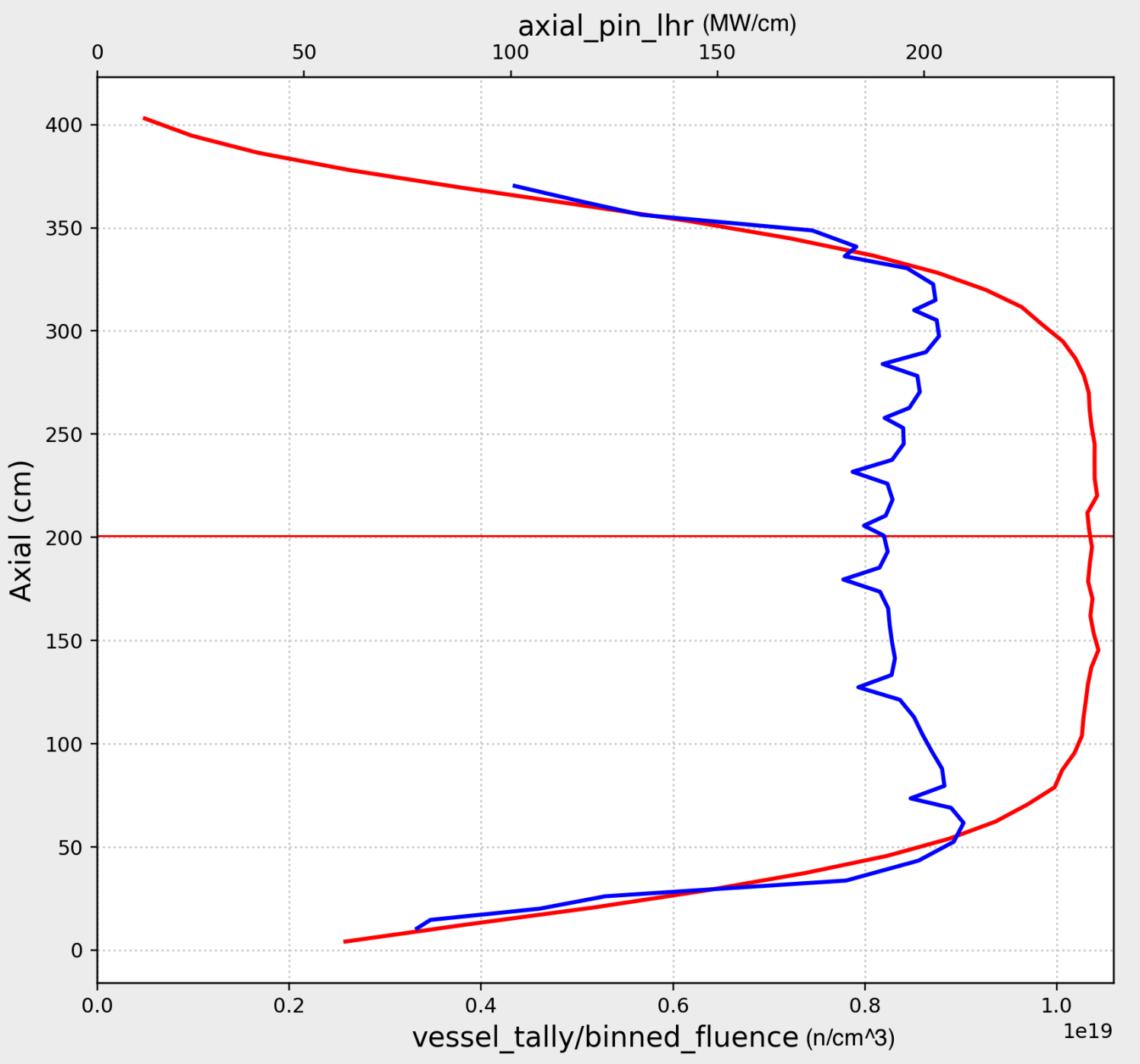

Figure 6. Axial vessel fluence and pin power for Watts Bar Unit 1 at EOC 15 plotted in VERAView. 


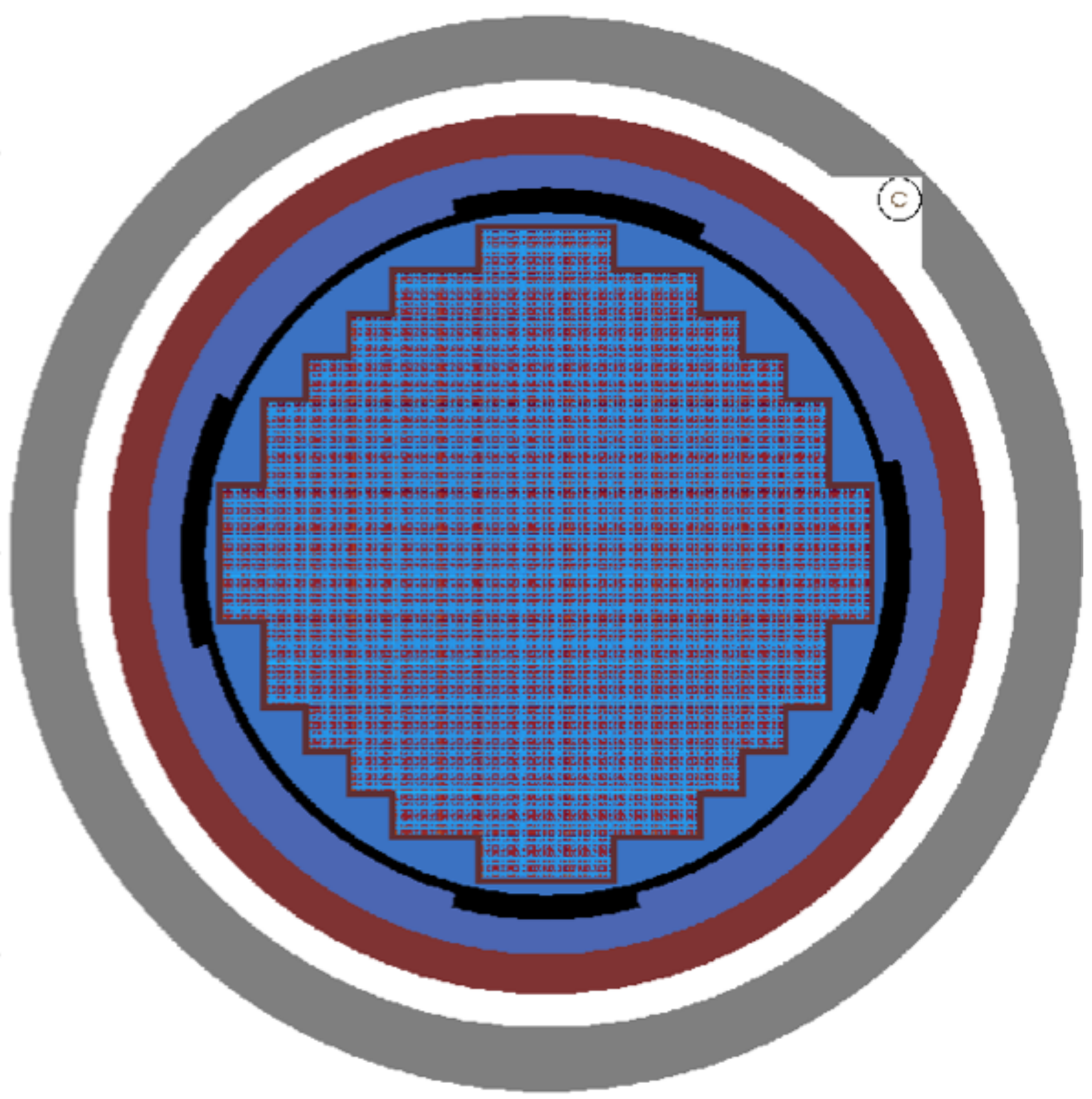

Figure 7. Axial slice of Harris PWR VERA model with excore detector (based on MCNP model provided by Duke Energy). 


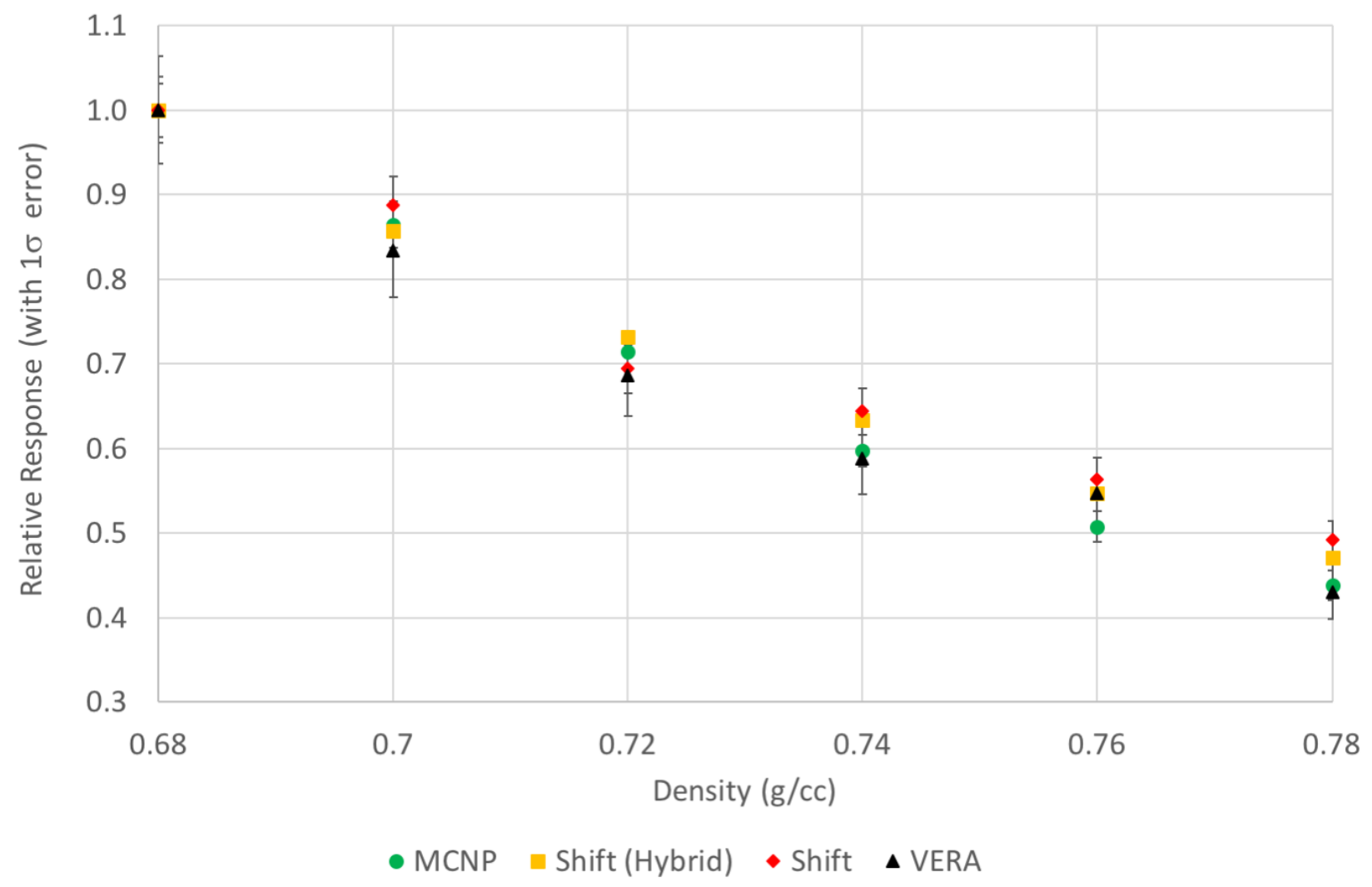

Figure 8. Calculated Harris PWR excore detector response change with moderator density. 
Verification of Vessel Fluence and Excore Modeling with VERA

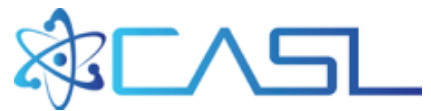

1. Finish integration and development of CADIS calculations using Shift through VERA for vessel fluence and excore detector calculations.

2. Add unit tests in Exnihilo and VERA.

3. Run AMA-p7, AMA-p9, and multicycle Watts Bar models, and calculate vessel fluence to show the implementation is complete.

4. Plot vessel fluence in VERAView.

5. Run modified Watts Bar model with excore detector for multiple cycles and tally flux and reaction rates. Plot these results using python to show that the implementation is complete.

6. Document the input, usage, output, and verification results.

Executables were delivered to AMA for verification and initial validation. The results included in this report for vessel fluence and excore detector response serve as evidence that this milestone has been completed.

\section{FUTURE WORK}

The one remaining issue mentioned in section 2 with excore detector calculations with CADIS is being resolved. Also, as mentioned in section 2, once the full consistent source biasing has been tested in Shift, it will be integrated into VERA. This will ensure a true CADIS calculation is being performed for excore calculations with VERA.

Further optimization will be undertaken to decrease solution time and to develop a more user-friendly interface. The main future task for vessel fluence and excore detector response is validation of results.

\section{REFERENCES}

[1] T. M. Pandya, T. M. Evans, K. Clarno, B. Collins, Excore Radiation Transport Modeling with VERA, Tech. Rep. CASL-U-2017-1311-001, CASL (November 2017).

[2] A. T. Godfrey, VERA Core Physics Benchmark Progression Problem Specifications, Tech. Rep. CASL-U-2012-0131-004, CASL (August 2014).

[3] T. M. Pandya, A. T. Godfrey, E. Davidson, Excore capabilities with VERA, CASL Industry Council Meeting Proceedings (April 2018).

[4] Westinghouse Electric Company, Analysis of Capsule Z from the Tennessee Valley Authority Watts Bar Unit 1 Reactor Vessel Radiation Surveillance Program, Tech. Rep. WCAP-16760-NP, NRC Public Report (2007).

[5] E. Davidson, T. M. Pandya, A. T. Godfrey, T. M. Evans, Testing of Omnibus General Geometry Models for Ex-Core Applications in VERA, Tech. Rep. CASL-U-2018-1561-000, CASL (April 2018). 
[6] H. Smith, A. T. Godfrey, E. Davidson, T. M. Pandya, Harris Nuclear Plant Ex-core NI Detector Response, CASL Industry Council Meeting Proceedings (April 2018).

[7] S. R. Johnson, T. M. Evans, G. G. Davidson, S. P. Hamilton, T. M. Pandya, Exnihilo transport code manual, Tech. Rep. Release 6.2.0 (Dev), Oak Ridge National Laboratory (2017).

[8] T. M. Pandya, T. M. Evans, K. Clarno, B. Collins, Excore Radiation Transport Modeling with VERA: Manual, Tech. Rep. CASL-U-2018-1556-000, CASL (April 2018). 